\title{
Challenges of the Intellectual Property System in the Age of Artificial Intelligence
}

\author{
Yin Fenglin, Zhao Yixin*, Medina Turdi \\ Department of Law and Intellectual Property, School of Public Policy and Management, University of Chinese Academy of Sciences, \\ Beijing, China \\ Email address: \\ yinfenglin666@126.com (Yin Fenglin),yvaine_law@126.com (Zhao Yixin), MedinAdina24@163.com (Medina Turdi) \\ *Corresponding author
}

\section{To cite this article:}

Yin Fenglin, Zhao Yixin, Medina Turdi. Challenges of the Intellectual Property System in the Age of Artificial Intelligence. American Journal of Applied Scientific Research. Special Issue: Science and Law (Review of Several Issues of Contemporary Science and Technology Law). Vol. 6, No. 1, 2020, pp. 24-29. doi: 10.11648/j.ajasr.20200601.13

Received: February 20, 2020; Accepted: March 6, 2020; Published: April 8, 2020

\begin{abstract}
In the 21st century, with the rapid growth of computer computing speed and the enhancement in cloud computing infrastructure, the artificial intelligence based on simulated human neural networks has developed to a new stage. Being the foundation and core of the new technological revolution, the artificial intelligence has been widely applied in economy, society and law areas. In the future, the artificial intelligence may completely emancipate the human beings by directly replacing human's mental activity to a certain degree. As the product of the development of science and technology, the intellectual property system develops continuously with the progress of science and technology. Due to the increasing scope and extent of the application of artificial intelligence in intellectual property work, it is likely to make a difference on the existing intellectual property system. However, the current intellectual property system in various countries are still based on the international conventions in the electrical age like Paris Convention for the Protection of Industrial Property (the 1967 Act) and the Berne Convention for the Protection of Literary and Artistic Works (the 1971 Act). Therefore, the artificial intelligence not only bring great challenges in the aspect of the subject, object and right content to the intellectual property system but also provide a few of new opportunities to this system.
\end{abstract}

Keywords: Artificial Intelligence, Intellectual Property System, Challenges, Opportunities, Subject, Object, Right Content

\section{Technology Development Trends in the Age of Artificial Intelligence}

\subsection{Artificial Intelligence Leads the Wave of Science and Technology}

Artificial intelligence is the ability of machines to execute functions that generally are associated with human intelligence. Up to the early 2010s, artificial intelligence technology advanced gradually [1]. And in December 2016, The Guardian declared the year 2016 as "the year artificial intelligence came of age.

Compared to 2016, the market scale of artificial intelligence of china had reached 23.74 billion yuan in 2017 . According to a report, in 2020, the global market scale will grow to a size of about $\$ 20$ billion. In order to upgrade the support of artificial intelligence to a national policy, the White House released the National Strategy on Artificial Intelligence in October 2016, and China also released "New Generation artificial intelligence Development Plan" in July 2017 [2]. As one of the basic tools of the new technology revolution, artificial intelligence is based on the integrated circuits, which follows the "Moore's Law", that is, the integrated circuits will double every two years or so. In addition, considering the increasingly powerful mechanical learning ability, the artificial intelligence will emancipate the human beings by directly replacing human's mental activity to a certain degree.

\subsection{Integrated Innovation and Secondary Innovation Leads the Wave of Innovation}

Because of the characteristic of looking-forward and complexity, during the process of executing functions that are associated with human intelligence, it is of great significance 
for the artificial intelligence to combine with lots of disciplines, such as Computer Science, Mathematics, Cognitive Science, Neuroscience and social science. On the one hand, other disciplines make a considerable impact in the research of the artificial neural network to turn mechanism into computer models, on the other hand, the landing of the artificial intelligence promotes the progress of burgeoning fields and traditional disciplines. Therefore, there will be more and more technology inventions and creations that are products of integrated technological innovation or secondary innovation.

\subsection{Individual Inventions Present Obvious "Segmented" Characteristics}

As mentioned above, in recent years, a great number of innovations are completed by researches in many fields rather than finish independently. Therefore, from the perspective of the global market, the inventions of each individual innovator are usually segmented, that is, the individual invention is only a segment of the innovation chain.

\subsection{Artificial Intelligence Brings Considerable Challenges to the Intellectual Property System}

Currently, the major legal origin of the intellectual property system in China and other countries in the world remains the Paris Convention for the Protection of Industrial Property (the 1967 Act) and the Berne Convention for the Protection of Literary and Artistic Works (the 1971 Act). Although the Agreement on Trade-related Aspects of Intellectual property rights is also a global foundation for international intellectual property rights, this agreement is based on the Paris Convention and the Berne Convention. Therefore, the artificial intelligence technologies not only bring great challenges to the operating intellectual property system but also shock the subject, object and right contents of the existing system.

\section{Challenges to the Aspect of Subject of the Intellectual Property System}

\subsection{Challenges to the Aspect of Subject of the Copyright Law}

Being customed to working with the Office system developed by Microsoft Corporation, humans have never worried that such auxiliary work software may shock the copyright legal system someday. However, in 2017, the poem "Sunlight Lost Glass" by the robot writer "Xiaobing" developed by Microsoft was officially published, and in 2019 , the "Nine Songs" artificial intelligence poetry writing system owned by Tsinghua University's Natural Language Processing and Social Human Computing Laboratory was launched, causing plenty of discussions among the professional writers such as "artificial intelligence writers are coming, do we need human writers in this era?"

The mental activities performed by artificial intelligence technologies encompass both cognitive and analytic activities
[3]. In fact, only when computers were able to recognize and make simple judgments did humans realize the contradictions between traditional copyright theory, that is, the copyright law in great number of countries merely protect the creation of natural person or at most legal person, and technological development. Robert C. Denicola had claimed that "Copyright law requires an identifiable human author because authors own copyrights and computers do not possess the personhood necessary to own property" in his article [4]. For instance, Japanese government had discussed this embarrassing issue in the Intellectual Property Promotion Plan 2016 and drawn the conclusion that it is of no possibility for artificial intelligence developers and users to preform their rights under the copyright law. On the contrary, the United Kingdom made express provision for copyright in computer-generated works, which were defined as works "generated by a computer in circumstances such that there is no human author [5]." Accordingly, with regard to other countries like Japan, the legislators need to break the stereotype and make some changes to avoid the loss of valuable works.

Some scholars think it feasible to analyze the originality of the computer-generated work firstly instead of paying close attention to the subject of the work [6]. According to other scholars, it is illogical to deny the copyright of computer-generated works because artificial intelligence is neither human nor material. Applying the relevant provisions of legal person to this issue maybe a wise choice, said a Chinese scholar [7].

In China's judicial field, different courts own different views on this issue. In the first case of artificial intelligence works in China, the Beijing Internet court held that although the articles involved in the case had certain originality, the originality was not a sufficient condition for literary works. And it was unrealistic to break through the basic norms of civil law, that is, only works created by natural persons were the objects protected by the copyright law [8]. In another case, Nanshan District People's Court of Shenzhen held that the article generated by artificial intelligence was reasonable in structure, clear in expression logic. Therefore, the articles involved in the case should be recognized as a legal person work with originality in the sense of copyright law.

Nevertheless, there exists a technical premise to discuss this matter, that is, to figure out the role of artificial intelligence in the process of the creating. Briefly, the mechanism of artificial intelligence can be summarized as follows: firstly, collect enough effective experimental data, and then apply the advanced algorithm to the data processing. In the process of data collection and processing of artificial intelligence, because of the lack of the common sense and a coherent "perception- cognition-judgment" thinking mode, the assistance of algorithm engineer is of great significance.

According to the Chinese Copyright Law, the man, who provides limited assistance to the work, is not the author. Consequently, being in an affiliating status, the artificial intelligence will not shake the foundation of copyright law completely, unless they know what they're doing. However, 
it is not to say that we should ignore the above challenge that artificial intelligence presents to copyright law.

As Annemarie Bridy says, the relatively slow development of artificial intelligence offers a reprieve from the reactive, crisis-driven model of policymaking that has dominated copyright law in the digital era [9].

\subsection{Challenges to the Aspect of Subject of the Patent Law}

Since the concept of "investment machine" [10] was proposed by Koza, an American scholar, the automatic generation artificial intelligence technology represented by the genetic programming, artificial neural network and robotics technology has accelerated the pace of invention. According to Reuters, the Legal Affairs Committee of the European Commission filed a motion on May 31, 2016, requiring the European Commission to identify at least the most advanced automated robots as "electronic people" and to give them "specific rights and obligations" [11]. Furthermore, a Japanese engineer, assisted by artificial intelligence, designed a new nose cone for the bullet train, improving the aerodynamic performance, the noise reduction level and the passenger experience [12]. It can be seen from the above examples that the technical scheme can be obtained better and faster with the aid of artificial intelligence.

Shakespeare once said: "man is the purification of the universe, the primacy of all things." Accordingly, there also exists a contradiction between traditional patent theory and technological development, that is, the pantentee can only be a natural person or a legal person. For an example, the United States emphasizes that"Whoever invents or discovers any new and useful process, machine, manufacture, or composition of matter, or any new and useful improvement thereof, may obtain a patent therefor, subject to the conditions and requirements of this title" [13].

Wang Zhengzhong, a Chinese scholar, stressed that it is an objective and independent issue to judge whether artificial intelligence itself can become the "subject" in the Patent Law- that is, when the inventions generated by computers are similar to human inventions in appearance and can meet the standards of patent authorization, it should be given the specific rights like humans [14]. Considering that there will be a serious legal logic error about the confusion of "subject" and "object" under the Patent Law, some Chinsese scholars suggest that it is practicable to grant the status of inventor to the developers or testors of artificial intelligence algorithm program [15].

\section{Challenges to the Aspect of Object of the Intellectual Property System}

\subsection{Challenges to the Aspect of Object of the Copyright Law}

With the rapid development of artificial intelligence, it is practicable for human beings to draw the picture, write the article and compose the music with the help of artificial intelligence. Therefore, whether the artificial intelligence creation can become the object of Copyright Law has become an increasingly concerned issue.

Accroding to the Copyright Laws in various countries, it is necessary for works to meet the originality standard of copyrightablity. Generally speaking, there exists a discrepancy between the civil law countries and the common law countries on the interpretation of the originality standard of copyrightablity. As more attention is paid to the author's spiritual rights, the requirements for the originality standard of works in civil law countries are stricter than those in common law countries. With regard to the artificial intelligence creation, the current controversy lies in the judgment order of this element and the subject element.

Some scholars claim that the object element in Copyright Law should be independent of the subject element, that is to say, when judging whether a work is original, it is unnecessary to first consider whether the creator of the work is a person or a machine. From the perspective of encouraging the development of science and technology, the author quite agree with this point of view. In fact, the Beijing Internet court and Shenzhen Nanshan District People's court mentioned above both hold that the artificial intelligence works involved in the case meet the originality standard of copyrightablity. Therefore, facing the challenge of artificial intelligence works, the current Copyright Law should unfold an objective and rational attitude.

\subsection{Challenges to the Aspect of Object of the Patent Law}

In 2016, IBM obtained 8088 patents in the United States, among which more than 2700 related to artificial intelligence and cognitive computing. According to the Article 22 of the Chinese Patent Law, inventions and utility models that are granted patent rights shall be novel, creative and practical. The challenge of artificial intelligence technology to the aspect of object of the current patent system mainly focuses on the examination standard of patent authorization.

Owing to the exponential growth of computer operation speed and the enhancement in cloud computing infrastructure, the artificial intelligence technology that has learned a lot of data is easier to find the invisible connection between data, which makes artificial intelligence assisted invention easier to meet the "novelty" standard of patentability. If other factors are not taken into account, this may lead to the invention of artificial intelligence being easily patented.

From the Guide to Patent Examination in China, it can be seen that the term "creativity" refers to the outstanding substantive characteristics and remarkable progress of the technology program itself. Consequently, there are two obstacles for patent examiners in the process of the examination of the creativity standard. Above all, affected by black box theory, it is laborious for patent examiners to discover the essential technical elements behind the invention, even under the premise of the disclosure of the technical program. Secondly, as such computer-generated inventions contain interdisciplinary expertise, it is impossible for patent 
examiners to examine the "creativity" of such inventions comprehensively and objectively from the perspective of "technicians in the art", which may result in the authorization of some junk patents.

When it comes to the utility standard of patentability, it is of great significance to realize one technical premise, that is, at the present stage, artificial intelligence cannot make value judgments like human beings due to the lack of common sense. In view of this, only with the help of human beings' value judgment can avoid patent application of technical programs such as "perpetual motion machine" and the disorder of patent market [16].

\subsection{Challenges to the Field of Big Data}

Under the impetus of artificial intelligence technology, big data has become a significant strategic resource for a company and a country. Today, the big data is regarded as the gold mine of the next stage of social development. However, in consideration of that big data can't be classified into a traditional intellectual property object, it can only be protected by trade secrets in many cases. Besides, there is a great deal of problems surrounding the ownership of big data, including data privacy and security issues. In this regard, whether it is possible to incorporate data that meets the characteristics of intellectual property into the intellectual property protection system and strengthen the privacy protection of big data becomes increasingly urgent.

\section{Challenges to the Aspect of Right Content of the Intellectual Property System: The Translation Right}

At present, machine translation, question answering system, dialogue system and automatic poem writing system are considered as the most difficult artificial intelligence tasks in NLP field. Taking machine translation as an example, from the use of expert system to the use of neural network, machine translation no longer needs to go through the steps of word alignment, phrase alignment, order adjustment, generation of translation content, no longer needs human processing logic, but can directly obtain the results of translation through the ability of deep learning, which is close to the level of human translation in some language pairs [17].

In 1886 , the provisions of the right of translation appeared in the Berne Convention for the first time [18]. Since then, in order to adapt to the new situation in the dissemination of works, the connotation and the protection period of translation right have been modified several times [19]. According to the Berne Convention, translation right mainly protects the right of the obligee to translate or authorize others to translate his works. Due to the continuous enhancement of deep learning technology, the continuous acceleration of computer operation, and the explosive growth of various types of data, the importance of automatic translation software developed on platforms such as Google is constantly emerging.

However, it is vital to have a clear understanding of the level of technological development, that is, the accuracy and logicality of machine translation are constantly improving, which needs only a few seconds to translate an article composed by human beings. Being accustomed to using automatic translation software, human beings have not realized that the use of automatic translation software may affect the interests of copyright owners to a certain extent. Some scholars may refute the negative impact of artificial intelligence technology on the translation right by virtue of the "reasonable use" system in the Copyright Law, nevertheless, it may not be difficult to see its clue by referring to the "copyright compensation" event in Germany.

When private reproduction becomes increasingly popular, in order to ease the strained relations between the copyright owner and the replicator, the German Supreme Court ruled that the recording equipment manufacturer should appropriately compensate the loss suffered by the copyright owner. According to the German Supreme Court, the conduct of private reproduction had constituted the infringement of the right of the copyright owner even if the users did not have the purpose of profit. Therefore, in 1965, the German Copyright Law established the system of "copyright compensation", which not only protected the private copy right, but also charged certain compensation to the party who provided the private copy equipment [20].

\section{Opportunities Brought by the Artificial Intelligence to the Intellectual Property System}

With the extensive application of new technologies in intellectual property work, while the artificial intelligence brings considerable challenges to the intellectual property system, it also brings a few of new opportunities and vitality to this system. At the same time, due to the increasing scope and extent of the application of these new technologies in intellectual property work, it is likely to make a difference on the existing intellectual property system. The typical performances are as follows:

\subsection{Artificial Intelligence Facilitates the Full Use of Intellectual Property Information}

Intellectual property information is an important part of the contemporary knowledge base. According to WIPO, global patent information can reveal more than $80 \%$ of the world's technological achievements [21]. Therefore, the full and effective use of global patent information is of paramount importance in avoiding repeated research.

For example, the U.S. patent and Trademark Office has established a shareable platform for users, which enables the users to achieve effective communication with others in variety of areas by the way of the disclosure of information on the progress of scientific research. 


\subsection{Artificial Intelligence Improves the Efficiency and Quality of the Intellectual Property Examination}

The major breakthrough, that artificial intelligence has made in graphic pattern recognition and text semantic analysis, can be applied at least to trademark review work. Optimistically, the wide application of artificial intelligence may cause revolutionary changes in the trademark registration system. In this way, the efficiency of trademark examination can be greatly improved, and the objectivity of it can be enhanced to a certain extent to prevent and reduce the unreasonably large hoarding registration.

\subsection{Artificial Intelligence has Outstanding Performance in Accurately Evaluating the Value of Intellectual Property}

The value of intellectual property lies in its use, which is the life of the intellectual property. Basing on the continuously self-optimized valuation model, the artificial intelligence is playing a vital role in evaluating the value of intellectual property by looking for rules through analyzing a large amount of data, setting information identification rules for computer learning and enabling computers to automatically identify and capture data and information related to evaluation, and drawing the value conclusion. This kind of artificial intelligence-based intellectual property value evaluation system can greatly reduce the cost of value evaluation, and thus effectively reduce the transaction cost of intellectual property users; on the other hand, the artificial intelligence intellectual property value evaluation system can effectively avoid natural person's subjective assessment by drawing the objective conclusion [22].

\subsection{Artificial Intelligence Technology Assists with Protecting Intellectual Property Rights Efficiently and Accurately}

Considering that the object of intellectual property is intangible, it is laborious for obligee to safeguard their lawful rights. Because of this embarrassing situation, traditionally, one of the main challenges of intellectual property protection is how to quickly and accurately monitor and detect infringers. According to the Nanjing Daily News, Jiangsu Future Network Innovation Research Institute has developed an intelligent search system for network videos and pictures, which can monitor and protect copyright works through Internet perception and big data analysis. In terms of information verification and pattern recognition, the speed and capacity of artificial intelligence have far exceeded the capabilities of natural persons. Therefore, it is convenient to use artificial intelligence to monitor the intellectual property infringement.

\section{Conclusion}

At present, being the foundation and core of the new technological revolution, the artificial intelligence has been widely applied in economy, society and law areas [23]. Under this circumstance, the intellectual property system with the human intellectual achievements as the protection object and the incentive innovation as the fundamental goal will be greatly challenged by the development and application of artificial intelligence. However, the change from the era of basic artificial intelligence to the era of general artificial intelligence still waits for an unforeseen opportunity. Therefore, only by calmly analyzing the challenges of artificial intelligence to the intellectual property system at this stage can we grasp the track of artificial intelligence and other technologies.

\section{References}

[1] Mizuki Hashiguchi. Artificial intelligence and the jurisprudence of patent eligibility in the United States, Europe, and Japan. Intellectual Property \& Technology Law Journal, 2017, (29): 3-12.

[2] Government of the People's Republic of China. New Generation artificial intelligence Development Plan.http://www.gov.cn/zhengce/content/2017-07/20/content_ 5211996.htm.

[3] Mizuki Hashiguchi. The global artificial intelligence revolution challenges patent eligibility laws. Journal of Business \& Technology Law, 2017, (13): 1-35.

[4] Robert C. Denicola. Ex machina: copyright protection for computer-generated works [J]. Rutgers University Law Review, 2016, (69): 251-286.

[5] Copyright, Designs and Patents Act, 1988, c. 48, § 178 (U.K.).

[6] Wang Qian. On the qualitative analysis of the content generated by artificial intelligence in copyright law. Legal Science (Journal of Northwest University of political science and law), 2017, 35 (05): 148-155 (in Chinese).

[7] Xiong Qi. Copyright recognition of artificial intelligence generated content. Intellectual property, 2017, (3): 3-8 (in Chinese).

[8] Beijing Internet Court (2018) Jing $0491 \mathrm{~min}$ NO. 239.

[9] Annemarie Bridy. Coding Creativity: Copyright and the Artificially Intelligent Author. Stanford Technology Law Review, 2012, (2012): 1-27.

[10] Ji Dongmei. The challenge of artificial intelligence invention to patent system -- Taking genetic programming as an example. Intellectual property, 2017 (11): 5 (in Chinese).

[11] Amir H. Khoury. Intellectualproperty rights for "hubots": on the legal implications of human-like robots as innovators and creators. Cardozo Arts and Entertainment Law Journal, 2017, (35): 635-668.

[12] BEN HATTENBACH, JOSHUA GLUCOFT. Patents in An Era of Infinite Monkeys and Artificial Intelligence. Stanford Technology Law Review, 2015, 19 (01): 35.

[13] 35 U.S.C. $§ 101$ (1952).

[14] Wang Zhengzhong. On the ownership of the rights of invention and creation generated by artificial intelligence - based on promoting the application of invention and creation. Electronic intellectual property, 2019 (02): 21-30 (in Chinese). 
[15] Zhu Xuezhong, Zhang Guangwei. Research on Patentability and ownership of technical achievements generated by artificial intelligence. Intelligence journal, 2018, 37 (02): 69-75 (in Chinese).

[16] Wu Handong, Zhang Ping, Zhang Xiaojin. The challenge of artificial intelligence to the legal protection of intellectual property. China legal review, 2018 (02): 1-24 (in Chinese).

[17] Huayu Yuandian Institute of legal artificial intelligence. Let legal people understand artificial intelligence.

[18] WIPO. Berne Convention for the Protection of Literary and Artistic Works. https://www.wipo.int/treaties/en/ip/berne/.

[19] David Vaver. Translation and Copyright: A Canadian Focus. http://digitalcommons.osgoode.yorku.ca/scholarly_works.
[20] Cao Shihua. Copyright compensation system in the digital age and its introduction. Legal science. Journal of Northwest University of political science and law, 2006 (06): 143-151 (in Chinese).

[21] Li Jianrong. Patent Literature and Information. Beijing: Intellectual Property Press, 2002: 531. (in Chinese).

[22] Tyron Stading. The Role of artificial intelligence in Intellectual Property.

https://www.ipwatchdog.com/2017/07/27/role-artificial-intelli gence-intellectual-property $/ \mathrm{id}=86085 /$.

[23] Loui RP. From Berman and Hafner's teleological context to Baude and Sachs'interpretive defaults: an ontological challenge for the next decades of artificial intelligence and Law. Dordrecht: Kluwer Academic Publishers, 2016. 